\title{
Trend Analysis of Area, Production and Productivity of Cherry in Jammu and Kashmir
}

\author{
Yasmeena Ismail $^{1 *}$, S.A. Mir ${ }^{1}$, Nageena Nazir ${ }^{1}$, M.H. Wani ${ }^{2}$, \\ S.A. Wani ${ }^{2}$ and M.S. Pukhta ${ }^{1}$ \\ ${ }^{1}$ Division of agricultural statistics, ${ }^{2}$ Division of Agri-Economics and HBM, Sher-e-Kashmir \\ University of Agricultural Sciences and Technology-Kashmir, India \\ *Corresponding author
}

Keywords

Cherry, Trend analysis, Parametric regression, Nonparametric regression

Article Info

Accepted:

18 January 2019

Available Online:

10 February 2019

\section{A B S T R A C T}

Cherry (Prunus avium) is one of the important horticultural crops grown in Jammu and Kashmir and is packed with healthy nutrients and excellent antioxidants. Basically, cherries are native to Europe and Asia regions. Cherries are cultivated all over the world and the top 3 producers of cherry are Turkey, USA and Iran. India occupies as $26^{\text {th }}$ producer in the list. In India, cherry commercial cultivation is carried in the states of Himachal Pradesh, Jammu and Kashmir and Uttar Pradesh due to suitable climate. The present study is an attempt to find past trends of cherry in Jammu and Kashmir using parametric, nonparametric and semi-parametric regression methods. The performance of each method is compared using higher values of $\mathrm{R}^{2}$ and lower values of residual criteria. It is found that the nonparametric/semi-parametric regression comes out to be good fit for trends in cherry production in comparison to the parametric regression. Even semiparametric spline regression is selected as the best fitted model for trend analysis. It is inferred that the area under cherry cultivation in Jammu and Kashmir is increasing from 1974-2017 and the productivity has also shown an increasing trend except for some recent years where the trend is found declining. The study advocates for researchers technological breakthrough in cherry production in Jammu and Kashmir.

\section{Introduction}

Cherries are one of the most important deciduous fruit as well as ornamental crop worldwide. In India, Cherries are mainly grown in the North-Western Himalayan region in the altitude range of 2,000 to 2,700 $\mathrm{m}$ above sea-level and require 1,000 - 1,500 $\mathrm{h}$ chilling period during winters. Climate of Jammu and Kashmir (J\&K), high hills of
Himachal Pradesh (H.P.) and Uttarakhand is ideal for its commercial cultivation. In Kashmir Harwan, Dara, Kangan, Shopian, Tangmarg, are the main areas where cherries are grown. The main cherry varieties grown in $\mathrm{J} \& \mathrm{~K}$ are Black Heart, Early Purple Black Heart, Guigne Noir Gross Lucenta, Guigne Noir Hative, Guigne Pour ova Precece, Bigarreau Napoleon and Bigarreau Noir Gross; whereas in H.P. Black Tartarian, Bing, 
Napoleon White, Sam, Sue, Stella, Van, Lambert, Black Republican, Pink Early, White Heart, Early Rivers, Nirodiro, Black heart, Cherry Red Sweet heart and Lambert are under cultivation. Bedford Prolific, Black Heart and Governor's Wood varieties are mainly cultivated in Uttarakhand.

The growth rates of crops are mostly estimated by the linear regression models. But there are instances where the linear regression models do not fit the data well. Under such situations it is essential to look for an alternative. The nonparametric and semiparametric approaches are more flexible in such situations. These approaches are particularly useful when little past experience is available. In last few years, nonparametric regression and semi-parametric regression technique for functional estimation has become increasingly popular as a tool for data analysis. These techniques impose only few assumptions about shape of function and therefore it is more flexible than usual parametric regression approaches. Smoothing techniques are commonly used to estimate the function non-parametrically (Härdle 1990). Nonparametric regression models avoid restrictive assumptions of the functional form of the regression function. Semi-parametric regression model combine the components of parametric and nonparametric regression models, by keeping the easy interpretability of the former and retains some of the flexibility of the latter. Various scientists viz., (Chandran 2004) has applied nonparametric regression to study the growth rates of total foodgrain production of India during the period 1987 to 2001. Teczan (2010) has studied the nonparametric regression technique to find out the growth rate trends of various crops. Sahu and Pal (2004) used nonparametric regression (Lowess) and semiparametric (spline) for modeling of pest incidences. (Dhekale, Sahu, Vishwajith, Mishra and Narsimhaiah 2017) employed the nonparametric regression model to study the trends of tea in India. The current study is aimed to develop appropriate parametric and nonparametric regression models to fit the trends in area, production and productivity. (Ismail, Mir and Nazir 2018) has utilized the nonparametric and semi-parametric regression models for modeling the trends in area, production and productivity of apple in Jammu and Kashmir.

\section{Materials and Methods}

For present study, to study the trends and growth rates, long term data for last 43 years pertaining to the area, production and productivity of cherry is collected from Directorate of Horticulture. The descriptive measures of central tendency and dispersions along with the simple and compound growth rates are used to explain the features of the data (Mishra, Sahu, Bajpai and Nirnjan 2012).

\section{Trend models}

\section{Parametric regression models}

To find out the path of the production process different parametric trend models are fitted. Among the fitted models, the best model is selected on the basis of their goodness of fit $\left(R^{2}\right)$ value and significance of the coefficients. The dependent variable $\mathrm{Y}$ is area, production and productivity of cherry and independent variable $\mathrm{X}$ is the time points (years) from 1974 to 2017.

\section{Nonparametric and Semi-parametric regression models}

The model considered here is of the form

$Y_{i}=m\left(x_{i}\right)+\varepsilon_{i}, x_{i}=i / n, i=1,2, \ldots n$

Where, $Y_{i}$ is observation of $i^{\text {th }}$ time point, $m(\cdot)$ is trend function which is assumed to be smooth and $\varepsilon_{i}$ are random errors with mean 
zero and finite variance. Since there is no assumption of parametric form of function $m(\cdot)$, this approach is flexible and robust to deviations from an assumed model form. To obtain an estimate of the mean response value at a point $X$, most of the smoothers are averaging the $\mathrm{Y}$ - values of observations having predictor values closer to the target value $X$. The averaging is done in neighborhoods around target value. The main decision to be made in any of the smoothing techniques is to fix the size of neighborhood which is typically expressed in terms of an adjustable smoothing parameter or bandwidth. Intuitively, large neighborhoods will provide an estimate with low variance but potentially high bias, and conversely for small neighborhoods.

Lowess regression, introduced by Cleveland (1979), is obtained on the basis of the data points around it within a band of certain width. The point $x_{i}$ is the midpoint of the band. The data points within the band are assigned weights in a way so that $\mathrm{x}_{\mathrm{i}}$ has the highest weight. The weights for the other data points decline with their distance from $\mathrm{x}_{\mathrm{i}}$ according to a weight function. The weighted least squares method is used to find the fitted value corresponding to $\mathrm{x}_{\mathrm{i}}$, which is taken as the smoothed value. The procedure is repeated for all the data points. The spline method of estimation make use of the penalized least squares method (Simonoff 2012), which balances the fitting of the data closely. The objective is to estimate $m$ by means of a function that fits the data well and is as smooth as possible. A measure of smoothness of $m$ is the integral of the square of its second derivative as

$$
\sum_{i=1}^{n}\left(Y_{i}-m\left(x_{i}\right)\right)^{2}+\lambda \int_{a}^{b}\left(m^{\prime \prime}(x)\right)^{2} d x
$$

Where $\lambda>0$ is a fixed constant and $x_{i} \in[a, b], i=1,2, \ldots . n$
The first term is the sum of squares of the residuals; it provides a measure of how well the function $m$ fits the data. The integral of the above equation is a measure for the roughness/smoothness of the function $m$. The functions which are highly curved will result in a large value of the integral; straight lines result in the integral being zero.

The roughness penalty $\lambda$, controls the emphasis which one wishes to place on smoothness. By increasing the value of $\lambda$, one places more emphasis on smoothness; as $\lambda$ becomes large the function approaches a straight line. On the other hand, a small value of $\lambda$ emphasizes the fit of $m$ to the data points: as $\lambda$ approaches a function that interpolates the data points.

\section{Results and Discussion}

The maximum growth rate is observed in production of cherry over the years, whereas the minimum growth rate is exhibited by productivity of the apple (Table 1). The positive compound growth of production (0.231percent per annum) reveals that there is no decrease in the production of cherry over the years with a maximum of 11.23 metric tones in 2013 and minimum of 0.51 metric tones in 1974 except for some exception for last few years where some fluctuation have been observed in the production of cherry. Similarly, the simple growth rate $(35.44$ per cent per annum) is observed in production indicates an increase in the production of cherry in Jammu and Kashmir over the years.

This is due to the fact that a large area of land is being brought under cultivation of cherry except for the years 2015 and 2016 the area under cherry cultivation has reduced. We have noticed a compound growth rate of area (0.034per cent per annum) under cherry cultivation indicating that a large portion of the land is being utilized for the latter (Fig. 1-5). 
Trend analysis of area, production and productivity

\section{Parametric techniques}

The linear models used here are the quadratic model or second degree polynomial model $Y_{t}=b_{0}+b_{1} t+b_{2} t^{2}$ and the cubic model or the third degree polynomial model $Y_{t}=b_{0}+b_{1} t+b_{2} t^{2}+b_{3} t^{3}$. The value of $b_{1}$ and $\mathrm{b}_{2}$ for area are negative which indicates that area under apple cultivation decreased in the initial and middle part of the cultivation period and the value of $b_{3}$ being positive clearly indicates that there was an increase in the cultivation area in the later part of the cultivation period. Further, the negative value $\mathrm{ofb}_{1}$ and $\mathrm{b}_{2}$ for production is an indication of the decrease in the production during the initial and middle period of the study and the positive values of $b_{3}$ indicates an increase in the production (Table 2 ).

\section{Nonparametric and semi-parametric regression}

Trend analysis of area, production and productivity using nonparametric (Loess) and semi-parametric (spline) regression are presented in the tables 3, 4 and 5. In Table 3 the value of $R^{2}$ is 0.97 for Loess and 0.95 for Spline regression. The $\mathrm{AIC}_{\mathrm{c}}$, RMSE, MAPE, MAE, MaxAPE and MaxAE values comes out be small for Loess and Spline regression in comparison with the parametric regression for the area under cherry cultivation. The area under the cherry cultivation has increased over the years of study except for some fluctuation in recent years and is shown in figure 1.

Table.1 Performance of cherry production in Jammu and Kashmir during 1974-2015

\begin{tabular}{|l|l|l|l|l|l|}
\hline \multicolumn{2}{|l|}{ Area ('000 hectare) } & \multicolumn{2}{l|}{ Production ('000 MT ) } & \multicolumn{2}{l|}{$\begin{array}{l}\text { Productivity } \\
\text { hectare) }\end{array}$} \\
\hline Maximum & 3.874 & Maximum & 1.1467 & Maximum & 4.93 \\
\hline Minimum & 0.654 & Minimum & 0.436 & Minimum & 0.51 \\
\hline Mean & 1.986 & Mean & 4.959 & Mean & 2.133 \\
\hline SD & 0.981 & SD & 3.929 & SD & 1.102 \\
\hline CV $(\%)$ & 4.94 & CV $(\%)$ & 7.92 & CV $(\%)$ & 5.16 \\
\hline Skewness & 0.362 & Skewness & 0.388 & Skewness & 0.140 \\
\hline Kurtosis & -1.074 & Kurtosis & -1.377 & Kurtosis & -0.848 \\
\hline SGAR (\%) & 7.755 & SGAR $(\%)$ & 35.440 & SGAR $(\%)$ & 6.384 \\
\hline CGAR (\%) & 0.034 & CGAR(\%) & 0.231 & CGAR $(\%)$ & 0.018 \\
\hline
\end{tabular}

Table.2 Trends in area, production and productivity of apple in Jammu and Kashmir

\begin{tabular}{|l|l|l|l|l|l|l|l|l|l|l|}
\hline & $\mathbf{R}^{\mathbf{2}}$ & $\begin{array}{c}\text { Constant } \\
\mathbf{b}_{\mathbf{0}}\end{array}$ & $\mathbf{b}_{\mathbf{1}}$ & $\mathbf{b}_{\mathbf{2}}$ & $\mathbf{b}_{\mathbf{3}}$ & $\mathbf{R M S E}$ & $\mathbf{M A P E}$ & $\mathbf{M A E}$ & MaxAPE & MaxAE \\
\hline Area & 0.93 & 21.09 & -11.64 & -23.22 & 0.962 & 8.34 & 5.45 & 7.32 & 19.56 & 27.10 \\
\hline Production & 0.87 & 16.22 & -21.99 & -43.22 & 0.930 & 10.67 & 2.67 & 16.56 & 3.67 & 39.54 \\
\hline Productivity & 0.90 & 7.42 & 33.67 & 0.76 & & 35.78 & 4.90 & 30.69 & 15.34 & 63.36 \\
\hline
\end{tabular}


Table.3 Trends in area of Apple in Jammu and Kashmir using non-parametric and semiparametric regression

\begin{tabular}{|l|l|lc|}
\hline & Loess & \multicolumn{2}{c|}{ Splines } \\
\hline Bandwidth & 0.18 & 0.95 & -2.40 \\
\hline $\mathbf{R}^{2}$ & 0.97 & & 0.99 \\
\hline AIC $_{\boldsymbol{c}}$ & 0.79 & 7.91 & \\
\hline RMSE & 0.13 & & 0.24 \\
\hline MAPE & 4.14 & 0 & \\
\hline MAE & 5.18 & 0.98 & \\
\hline MaxAPE & 17.79 & 0.29 & \\
\hline MaxAE & 0.48 & \multicolumn{2}{|c|}{} \\
\hline
\end{tabular}

Table.4 Trends in production of Cherry in Jammu and Kashmir using non-parametric and semiparametric regression

\begin{tabular}{|l|l|l|}
\hline & Loess & Splines \\
\hline Bandwidth & 0.27 & 0.67 \\
\hline $\mathbf{R}^{\mathbf{2}}$ & 0.95 & 0.93 \\
\hline AIC $_{\mathbf{c}}$ & 14.96 & 10.67 \\
\hline RMSE & 0.69 & 0.73 \\
\hline MAPE & 0.20 & 0.21 \\
\hline MAE & 0 & 0.002 \\
\hline MaxAPE & 0.11 & 0.11 \\
\hline MaxAE & 2.66 & 2.87 \\
\hline
\end{tabular}

Table.5 Trends in productivity of cherry in Jammu and Kashmir using non-parametric and semiparametric regression

\begin{tabular}{|l|l|l|}
\hline & Loess & Splines \\
\hline Bandwidth & 0.36 & 7.83 \\
\hline R $^{2}$ & 0.95 & 0.89 \\
\hline AIC $_{\mathbf{c}}$ & 0.63 & 0.82 \\
\hline RMSE & 0.62 & 0.71 \\
\hline MAPE & 0.27 & 0.33 \\
\hline MAE & 0.002 & 0.22 \\
\hline MaxAPE & 0.14 & 0.19 \\
\hline MaxAE & 2.68 & 2.93 \\
\hline
\end{tabular}


Fig.1 Observed and expected trends of area under cherry cultivation using spline in Jammu and Kashmir

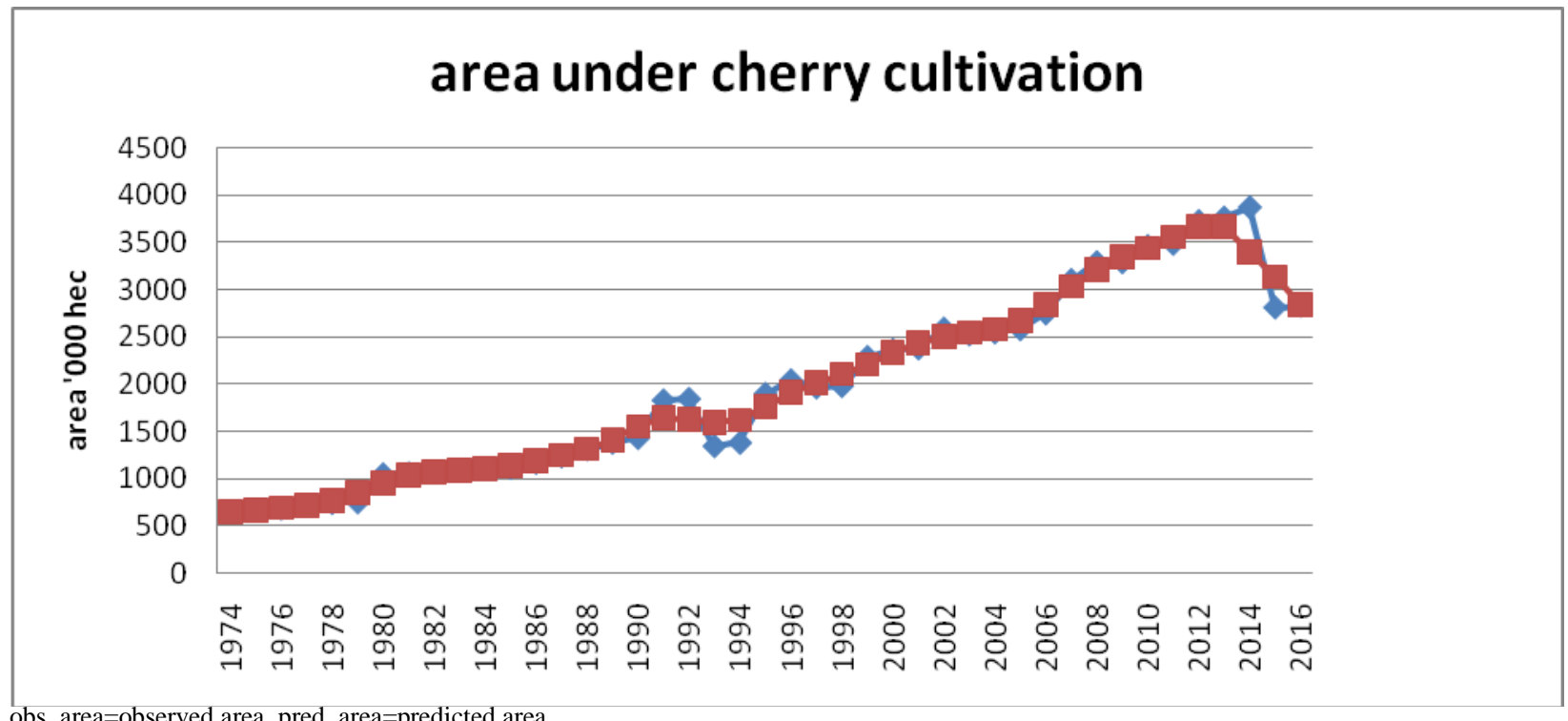

obs_area=observed area, pred_area=predicted area

Fig.2 Fits with specified smooths for area

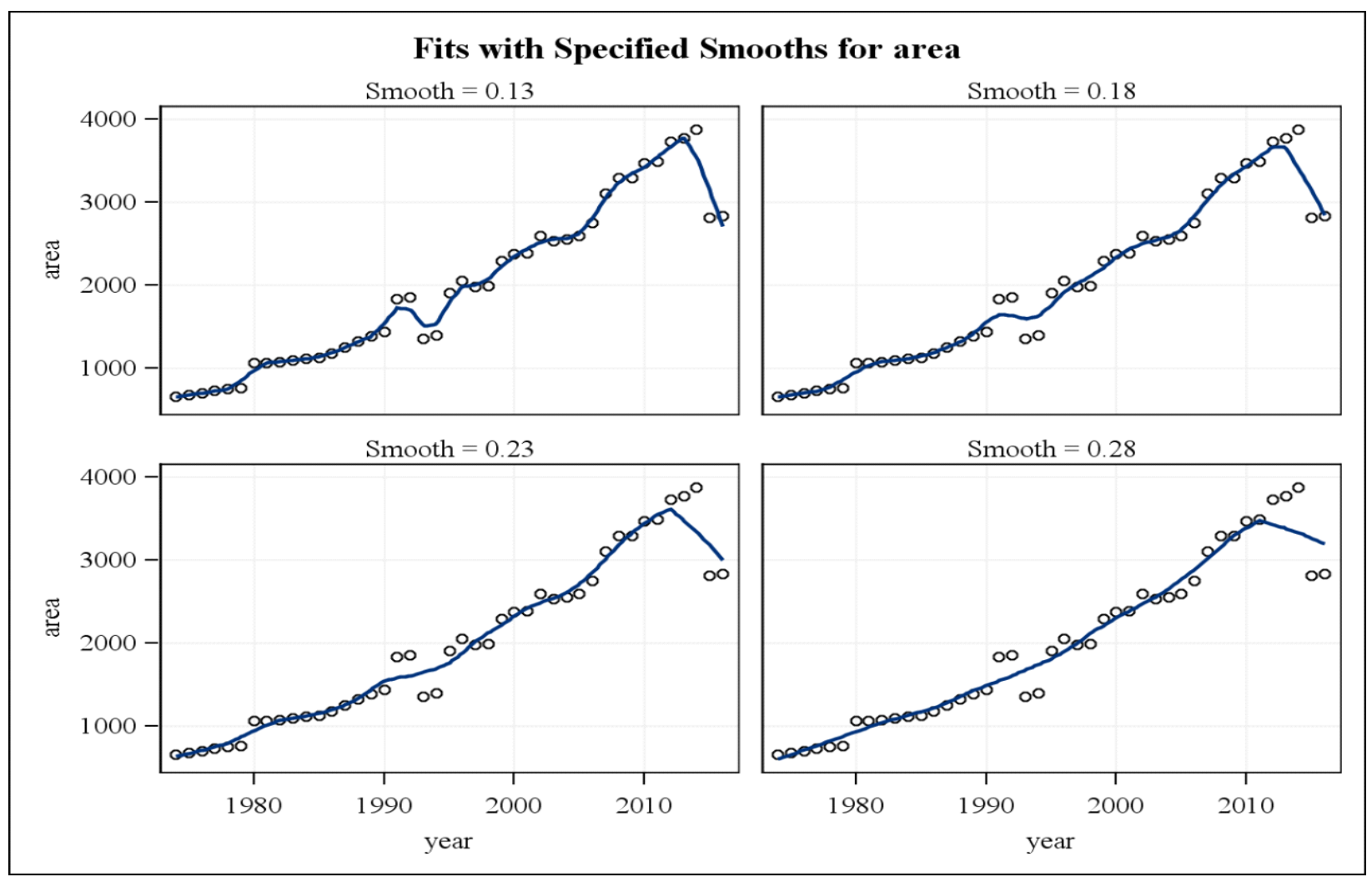


Fig.3 Observed and expected trends of production of cherry using splines

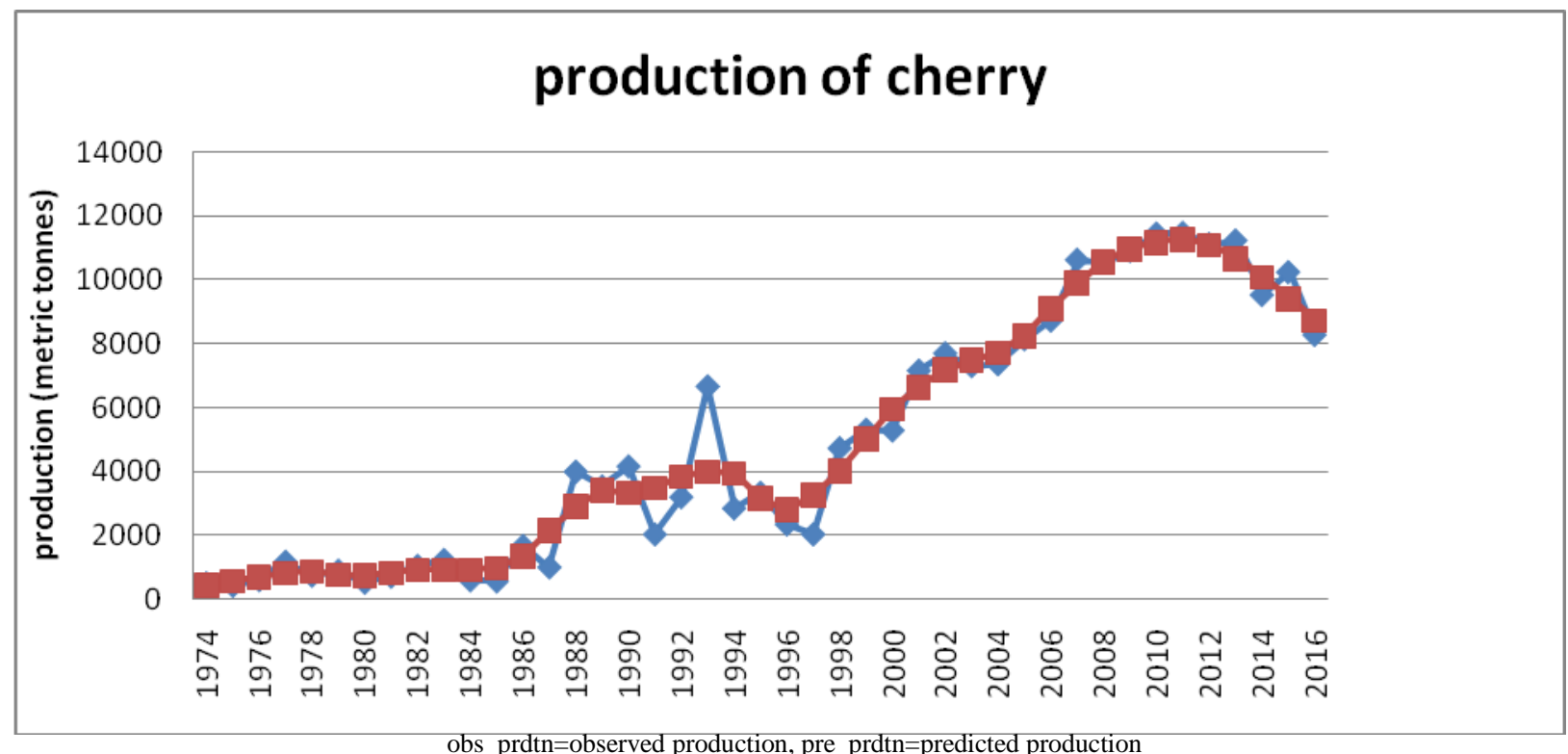

Fig.4 Fits with specified smooths for production

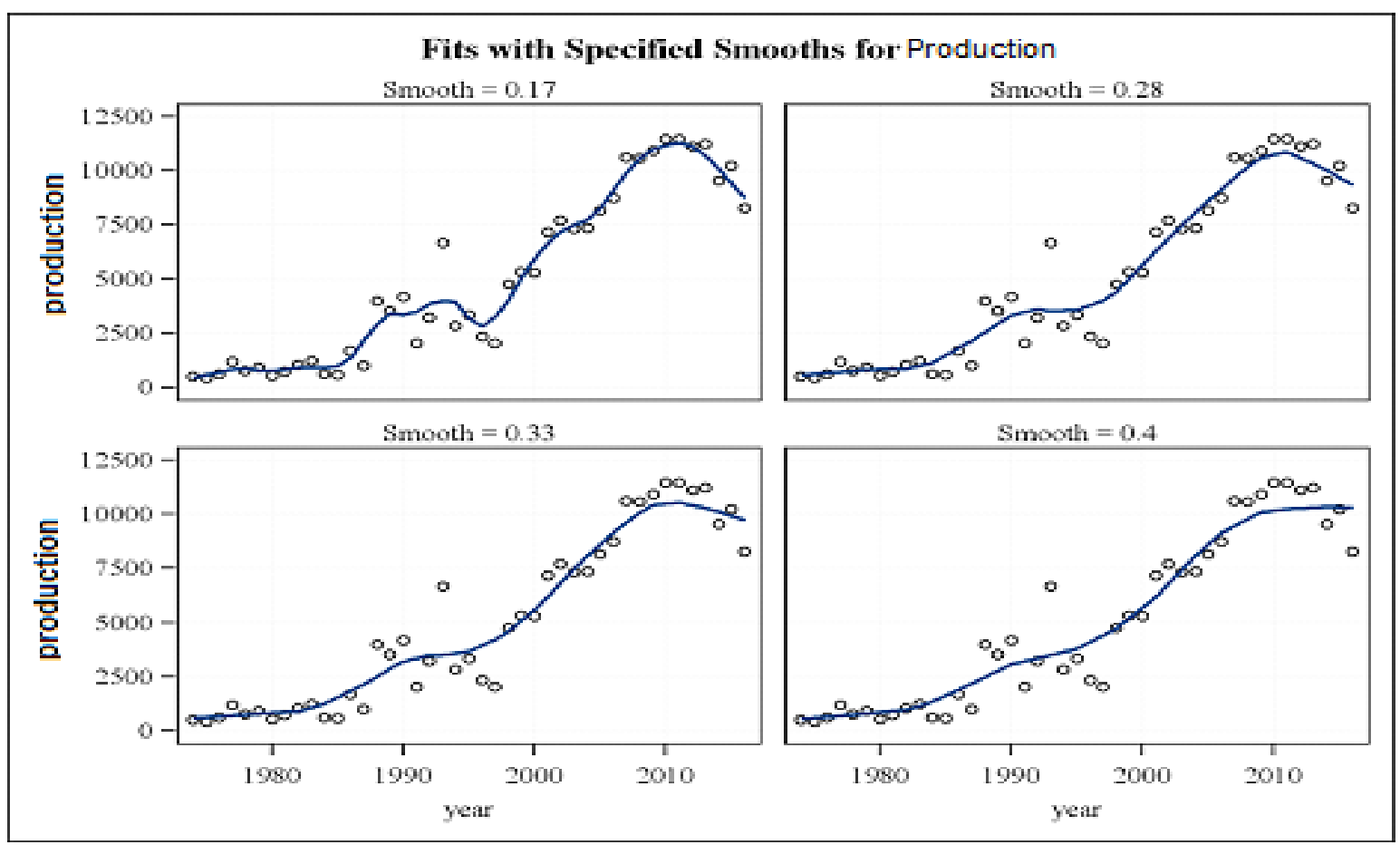


Fig.5 Observed and expected trends of productivity of cherry using spline

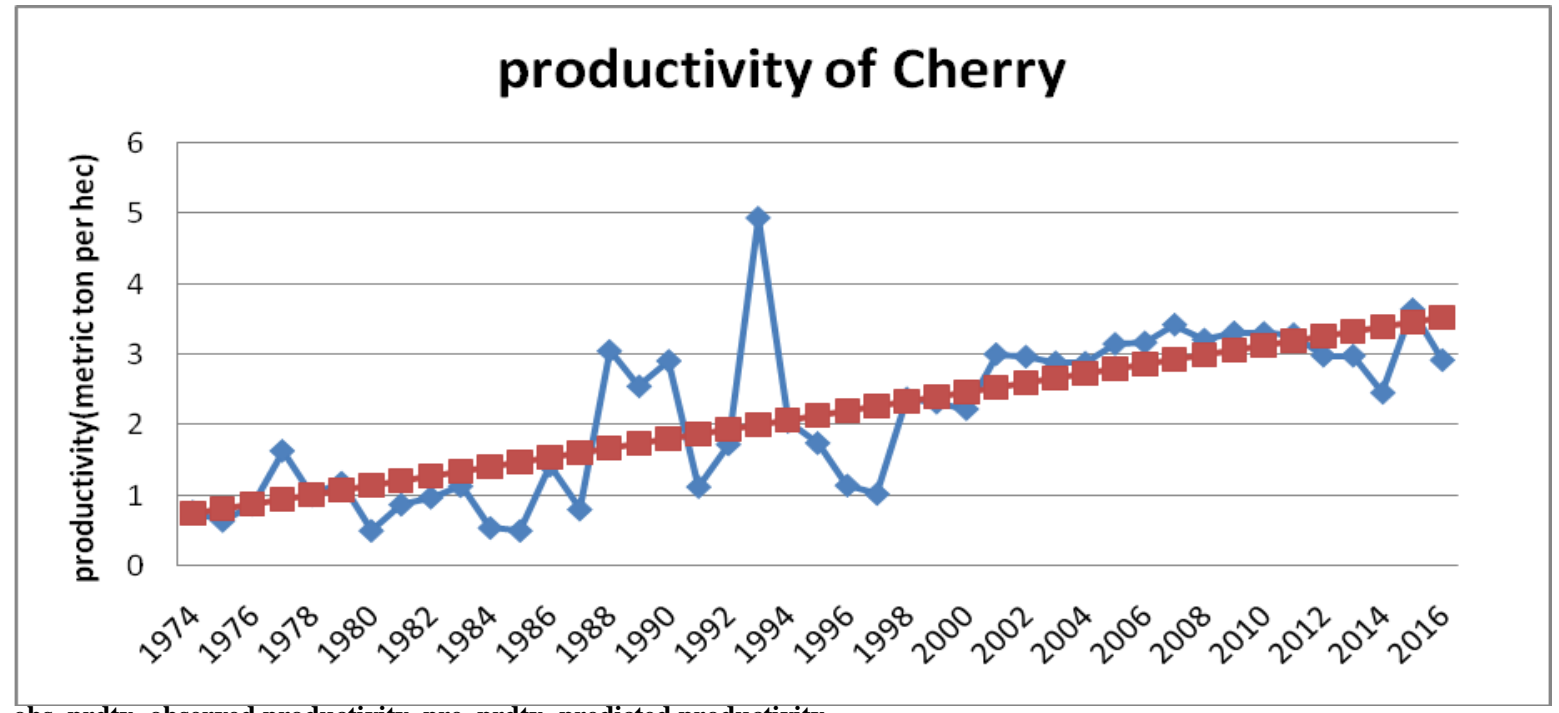

obs_prdty=observed productivity, pre_prdty=predicted productivity

Fig.6 Fits with specified smooths for productivity

\section{Fits with Specified Smooths for productivity}
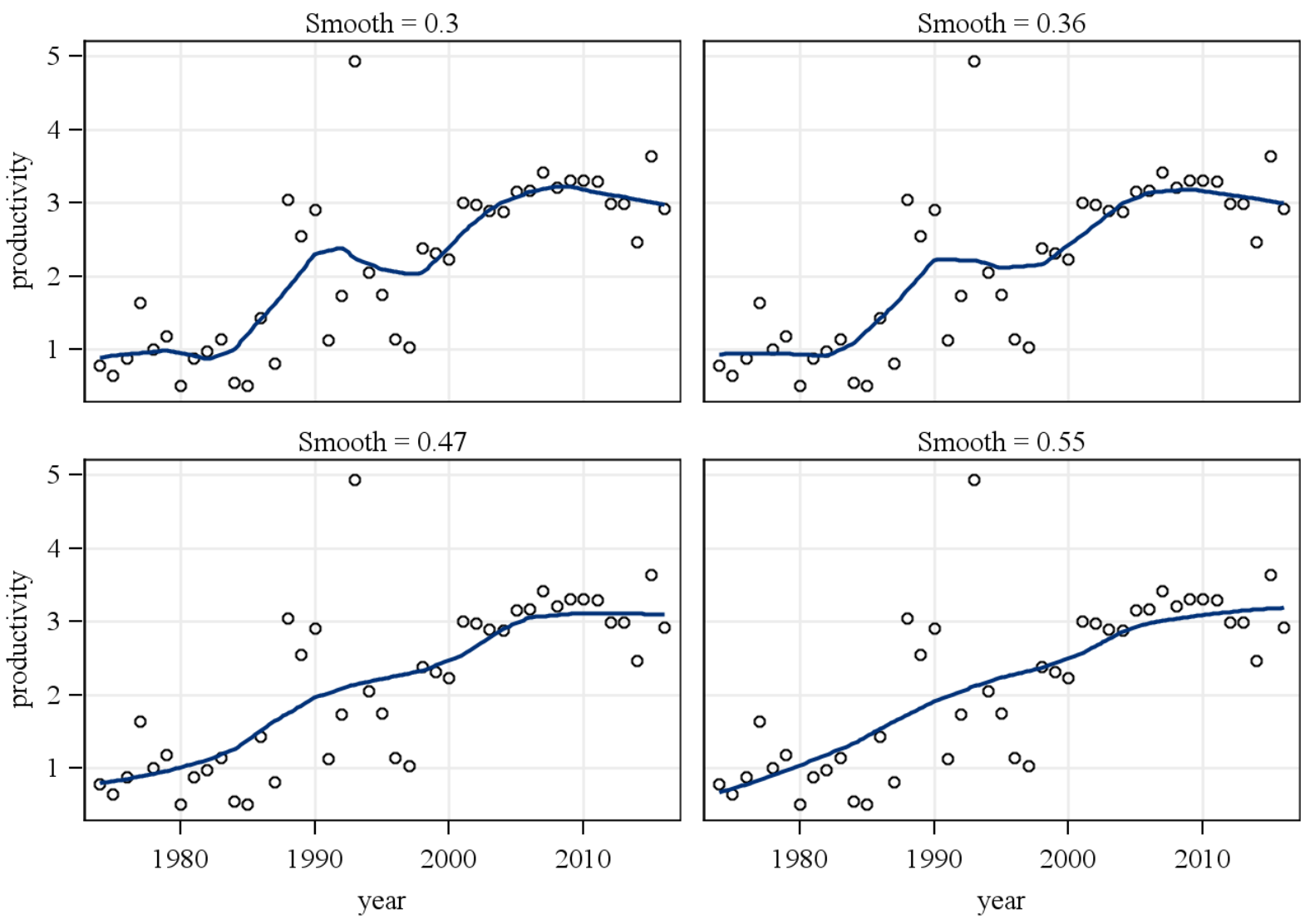
On comparing the values of $\mathrm{AIC}_{\mathrm{c}}$, RMSE, MAPE, MAE, MaxAPE and MaxAE for production and productivity the loess and spline regression has the smallest values. Area under Fruits in J\&K State has increased from 85508 hectares in $1975-76$ to 205543 hectares in 1995-96 and the production has increased from 375068 MTs in 1975-76 to 968640 MTs in 1995- 96, which further increased to 283084 hectares (area) and 1504011 (production) MTs in 2006-07. During 201516 the area under fruits in J\&K was 337677 hectares and production was 2493999 MTs, recording an increase of $64.28 \%$ in area and $47 \%$ in production during the last two decades(Islam and Shrivastava 2017). The production of cherry has increased manifold in the last decade. In 2005-2006, 2880 metric tonnes of cherry were produced which jumped to 11,629 metric tonnes in 2012. The increase is due to the increase in the area of production which includes Tangmarg, Dara and Nishat belt. Also, the plantation provided to growers under Horticulture Mission for North and East Himalayan States (HMNEH) scheme have proved beneficial.

The values of area are initially fitted at the smoothing parameters in order to obtain the best fit of the data points we obtain the graph of the data points in the neighborhood of the smoothing parameters and look for the curve which covers all the points of the data. The one which covers maximum points is the best fit of the data points. In figure 2 the smooth curve fits are obtained for area in the neighborhood of smoothing parameters i.e., at $0.13,0.18,0.23$ and 0.28 . It is observed that the best fit is obtained at smooth $=0.18$. In figure 4 smooth fits for production are plotted in the neighborhood of the smoothing parameter at $0.17,0.28,0.33$ and 0.40 and it is observed that the best fit obtained for smooth $=0.28$.

Figure 6 provides the fits for productivity in the neighborhood of the smoothing parameters i.e., at smooths equal to 0.30 , $0.36,0.47$ and 0.55 . The best fit is observed to be at the smooth=0.36. Even values of RMSE, MAE, MAPE, MaxAE and MaxAPE for area, production and productivity of cherry in Jammu and Kashmir for non-parametric regression has observed lower values than the parametric regression (Tables 3, 4 and 5). This is clear indication of the superiority of these techniques over the parametric models. These models perform very well in visualizing the past trends where the parametric models fails to.

Among the nonparametric and semiparametric regression, the spline regression has shown the lowest values of $\mathrm{AIC}_{c}$, RMSE, MAPE, MAE, MaxAPE and MaxAE for area, production and productivity of cherry in Jammu and Kashmir. Hence spline regression is the best fitted model for cherry production in Jammu and Kashmir. Various scientist viz. Aydin (2007) and Pal (2011) observed similar results where the spline gave the better results than the Loess smoothing.

From the above study, it is observed that there is dramatic increase in the area under apple cultivation and with a sudden decrease in the production as well as productivity in recent years. In order to maintain the trend more and more land is to be brought under the cherry cultivation. Parametric regression usually utilized in studying the trend seems not to perform better than the nonparametric and semi-parametric regression. And out of the nonparametric and semi-parametric regression methods the semi-parametric regression (spline) is the best fit for the trend analysis of the apple production of Jammu and Kashmir.

\section{References}

Aydin D 2007. A comparison of the nonparametric regression models using 
smoothing spline and kernel regression. World Academyof Science, Engineering and Technology 36: 253-57.

Chandran, K. (2004), "A Study on Some Aspects of Nonlinear Statistical Models in Agriculture," Indian Agricultural Statistics Research Institute Indian Agricultural Research Institute: New Delhi.

Cleveland WS 1994. The elements of graphing data (revised edition). Hobart Press, Summit, NJ, USA.

Dhekale, B., Sahu, P., Vishwajith, K., Mishra, P., and Narsimhaiah, L. (2017), "Application of Parametric and Nonparametric Regression Models for Area, Production and Productivity Trends of Tea (Camellia Sinensis) in India," Indian Journal of Ecology, 44, 192-200.

Härdle, W. (1990), Applied Nonparametric Regression, Cambridge university press.

Islam, R. T., and Shrivastava, S. (2017), "A Study on Area, Production and Productivity of Apples in J\&K from 2006-07 to 2015-16," International Journal of Scientific Research and Management, 5, 6513-6519.

Ismail, Y., Mir, S., and Nazir, N. (2018), "Utilization of Parametric and
Nonparametric Regression Models for Production, Productivity and Area Trends of Apple (Malus Domestica) in Jammu and Kashmir, India," Int. J. Curr. Microbiol. App. Sci, 7, 267-276.

Mishra, P., Sahu, P., Bajpai, P., and Nirnjan, H. (2012), "Past Trends and Future Prospects in Production, and Export Scenario of Tea in India," International Review of Business and Finance, 4, 2533.

Pal S 2011. Modeling Pest Incidences in Some Agricultural Crops, Thesis Submitted to the Bidhan Chandra Krishi Viswavidyalayaunder Department of Agricultural Statistics

Sahu PK and Pal S 2004. Modelling Pest Incidence - Nonparametric Approach. Paper presented in 24th International Symposiumon Forecasting, Sydeny

Simonoff, J. S. (2012), Smoothing Methods in Statistics, Springer Science \& Business Media.

Teczan N 2010. Analysis of the Factors Affecting Productivity Using Non Parametric Regression Method. $10^{\text {th }}$ Global Conference onBusiness \& Economics, Rome, Italy

\section{How to cite this article:}

Yasmeena Ismail, S.A. Mir, Nageena Nazir, M.H. Wani, S.A. Wani and Pukhta, M.S. 2019. Trend Analysis of Area, Production and Productivity of Cherry in Jammu and Kashmir. Int.J.Curr.Microbiol.App.Sci. 8(02): 2135-2144. doi: https://doi.org/10.20546/ijcmas.2019.802.247 